\title{
Atenção plena no contexto escolar: benefícios e possibilidades de inserção
}

\author{
Gustavo Matheus Rahal', https://orcid.org/0000-0002-0362-2978
}

\begin{abstract}
Resumo
O objetivo deste trabalho é investigar a prática da atenção plena em contexto escolar através da análise de trabalhos publicados sobre o tema. O desenvolvimento de habilidades em atenção plena vem ao encontro das iniciativas que visam trabalhar na escola as capacidades sócioemocionais. A prática da atenção plena já foi correlacionada à sensação de felicidade assim como a divagação mental, seu oposto, correlacionada a maiores níveis de insatisfação pessoal. A metodologia adotada para este artigo foi a pesquisa exploratória com coleta de dados por meio de pesquisa bibliográfica e deste levantamento foram identificados cinco programas distintos de intervenção e os mesmos foram descritos e analisados neste trabalho. Conclui-se destacando que as intervenções pesquisadas são bastante diversas em sua estrutura e temática dos encontros, porém, todas demonstram alguma eficácia. A comparação das intervenções entre si a fim de identificar as mais efetivas tornou-se difícil porque mensuram diferentes constructos usando variados instrumentos de medição.
\end{abstract}

Palavras-chave: Adolescência; atenção plena; infância.

\section{Mindfulness in the school context: Benefits and possibilities of integration}

\begin{abstract}
The objective of this study is to investigate the practice of mindfulness in a school context through the analysis of published works on the subject. The development of abilities in mindfulness meets the initiatives that aim to work in the school the socio-emotional capacities. The practice of mindfulness hás already been correlated with the feeling of happiness as well as the mental ramification, its opposite, correlated to higher levels of personal dissatisfaction. The methodology adopted for this article was the exploratory research with data collection through bibliographical research and from this survey Five distinct intervention programs were identified and the same were described and analyzed in this work. It concluded that the interventions studied are quite diverse in their structure and thematic of the meetings, but all show some effectiveness. Comparing the interventions with each other to identify the most effective ones has become difficult because they measure different constructs using various measuring instruments.
\end{abstract}

Keywords: Adolescence; childhood; mindfulness.

\section{Atención plena em el contexto escolar: beneficios y posibilidades de inserción}

\section{Resumen}

El objetivo de este estudio es investigar la práctica de la atención plena en contexto escolar por intermédio del análisis de estudios publicados sobre el tema. El desarrollo de habilidades em atención plena viene al encuentro a iniciativas que visan trabajar em la escuela las capacidades socio-emocionales. La práctica de la atención plena ya fue correlacionada la sensación de felicidad, así como la divagación mental, su opuesto, correlacionada a mayores niveles de insatisfacción personal. La metodología adoptada para este artículo fue la investigación exploratória com recolecta de datos por intermedio de investigación bibliográfica y de este levantamiento fueron identificados cinco programas distintos de intervención y estos fueron descritos y analizados en este estudio. Se concluye destacando que las intervenciones investigados son bastante diversas em su estructura y temáticas de los encuentros, sin embargo, todas demuestran alguna eficacia. La comparación de las intervenciones entre sí a fin de identificar las más efectivas se volvió difícil porque mensurar diferentes constructos usando variados instrumentos de medición. Palabrasclave: Adolescencia; infancia; atención plena.

1 Instituto Federal do Paraná - Foz do Iguaçu - Paraná - Brasil; grahal@me.com 


\section{Introdução}

Atenção plena, também conhecida como mindfulness, é uma forma de se relacionar com a experiência presente, envolvendo tanto a habilidade de prestar atenção de maneira intencional e sem julgamento ao que acontece momento-a-momento, quanto ao desenvolvimento da própria faculdade de estar atento ou consciência (awareness). Nas últimas décadas vem tendo especial destaque dentro de alguns ramos da ciência, particularmente da Medicina, Neurociências e Psicologia.

$\mathrm{Na}$ Psicologia, essa prática e seu desdobramento para a saúde mental começou a ser pesquisada, e então integrada à Psicoterapia, já no início do século XX. Apesar de Freud e Carl Jung terem tido contato com escritos do budismo (Germer, Siegel, \& Fulton, 2016) foi Roberto Assagioli, no ano de 1910, o pioneiro a integrar conhecimentos da Psicologia Budista e Zen, em especial o uso da meditação, incluindo a atenção plena, em um elaborado sistema de psicoterapia chamado de Psicossíntese (Assagioli, 2013). Ao longo do século $X X$ as pesquisas na área da meditação foram tomando corpo, porém, apenas na década de 1990 a preponderância dos estudos mudou para a meditação mindfulness especificamente (Germer \& cols., 2016). Intervenções empiricamente validadas nessa área surgiram inicialmente no contexto hospitalar com o foco na redução de estresse de profissionais da saúde (Kabat-Zinn \& cols., 1992).

Atualmente a atenção plena tem sido empregada de maneira central em diversas abordagens psicoterapêuticas. Como exemplos tem-se a Terapia Cognitiva-Comportamental baseada em mindfulness e aceitação (Lizabeth \& Orsillo, 2010), a Terapia Comportamental Dialética (Linehan, 2015), a Terapia de Aceitação e Compromisso (Hayes, Strosahl, \& Wilson, 2012), o Programa mindfulness para redução de estresse (MBSR) (Kabat-Zinn, 2013), a terapia de Prevenção de Recaída Baseada em Mindfulness (MBRP) (Bowen, Chawla, \& Marlatt, 2010), a Terapia da Compaixão (Gilbert, 2010) e mais recentemente a integração com abordagens psicodinâmicas (Stewart, 2014).

As pesquisas sobre a aplicação desta prática no contexto escolar são mais recentes, porém, promissoras. Zenner, Herrnleben-kurz e Walach (2014) apontam importantes benefícios da aplicação da atenção plena no contexto escolar como a melhora da performance cognitiva e o aumento da resiliência ao estresse. Intervenções baseadas em atenção plena também se mostram promotoras de bem-estar psicológico (Brown \& Ryan, 2003).

No Brasil a temática ainda é pouco estudada e, no contexto escolar, praticamente não existem pesquisas e aplicações. Neste sentido, é importante entender e buscar formas de intervenção que possam ser aplicadas à realidade escolar brasileira. Diante deste cenário, objetivou-se investigar a prática da atenção plena em contexto escolar, delimitando-se a pesquisar intervenções que pudessem ter eficácia comprovada. Para tanto se tomaram como referên- cia duas metanálises publicadas até então, e avaliaram-se algumas das intervenções apresentadas por elas.

\section{Concepções de Atenção Plena}

Atenção plena é a tradução do termo inglês mindfulness e se refere a "uma consciência sincera, de momento a momento, não julgadora" (Kabat-Zinn, 2005). Já o termo mindfulness é uma tradução para o inglês da palavra sati, empali, sendo esta a língua da Psicologia Budista há 2,5 mil anos (Germer \& cols., 2016). Esse conceito é o ensinamento central dessa tradição. Apesar do surgimento a partir de tradições budistas, passou a ser empregado dentro das ciências ocidentais de maneira secular e refere-se à capacidade de prestar atenção, no momento presente, a tudo o que surgir interna ou externamente, sem se prender em julgamentos ou desejar que as coisas fossem diferentes (não aceitação) (Kabat-Zinn, 2003). Essa habilidade é especialmente útil em psicoterapia porque permite que a pessoa aprenda a tomar consciência das experiências internas de uma maneira mais saudável. É também terapêutica, porque ajuda a promover a aceitação da experiência interna e assim diminuir a chamada evitação experiencial (Hayes \& cols., 2012), fator que está relacionado a uma grande variedade de psicopatologias.

É importante enfatizar também o que não é atenção plena. William \& Penman (2015) destacam seis mal entendidos comuns quando se fala em atenção plena (ou meditação): (1) apesar de ter se desenvolvido principalmente dentro de tradições milenares como o Budismo, a loga e o Taoísmo, a atenção plena não é uma religião, mas sim um método de treinamento mental e um modo de ser momento-a-momento; (2) não é complicado ou obscuro (o que não quer dizer que seja fácil) e não tem a ver com "sucesso" ou "fracasso" por chegar em algum estágio ou estado; (3) não vai entorpecer a mente nem atrapalhar seus objetivos de vida fazendo você adotar uma postura passiva ou resignada diante da vida;(4) não implica em aceitar o inaceitável, mas sim, ver o mundo com clareza para ser capaz de tomar atitudes mais sábias, para mudar o que precisa ser mudado; (5) não é uma técnica de distração visto que trabalha justamente o oposto, a atenção ao momento presente; (6)e também não é uma busca por relaxamento apesar deste acontecer como subproduto da prática.

O foco em atenção plena dentro da ciência tem décadas, porém um consenso sobre uma definição operacional testável para mindfulness surgiu apenas na publicação de Bishop e cols. (2004). Neste consenso chegou-se a uma definição que engloba dois componentes principais: uma atenção sustentada ao momento presente e uma atitude de abertura, curiosidade e aceitação. Desta forma, quando se aplica e pratica a atenção plena, busca-se trabalhar estes dois componentes, sendo que ambos, apesar de relacionados, são independentes um do outro, característica demonstrada durante a construção de uma das principais escalas 
de mensuração de atenção plena, a Escala Filadélfia de Mindfulness (Silveira, Castro, \& Gomes, 2012).

\section{Efeitos Neurobiológicos da Prática da Atenção Plena}

Apesar de fugir do escopo deste trabalho detalhar alterações neurais e fisiológicas decorrentes da prática da atenção plena, é importante destacar alguns achados. Lazar (2016) apresenta uma acessível síntese de estudos em relação à neuroplasticidade, apontando mudanças tanto na atividade quanto na estrutura cerebral. A diminuição da atividade na rede em modo padrão (RMP) aparece de maneira consistente em diversos estudos que investigaram praticantes de meditação. Essa rede tem papel importante na criação do sentido de self, além de gerar pensamentos espontâneos enquanto a mente vagueia, portanto, sua desativação é consistente com as práticas em atenção plena que buscam minimizar o desvio mental (Lazar, 2016). Em relação à estrutura cerebral, meditadores de longo prazo apresentam aumento na insula anterior, envolvida na observação de sensações físicas internas, e no córtex sensorial, relacionada à observação de sensações físicas externas (Lazar, 2016). Há também diminuição da densidade da substância cinzenta da amígdala, região conhecida por desempenhar um papel importante na regulação emocional.

Por fim, a prática da atenção plena baseia-se em grande medida na respiração lenta, tanto para treinar a atenção aproveitando-se do ritmo constante e contínuo dessa atividade fisiológica quanto pelo seu efeito de relaxamento. Dada sua relevância, alguns estudos buscaram isolar o efeito de um treino somente baseado na respiração lenta. Pal, Velkumary \& Madanmohan (2004), por exemplo, fizeram um estudo que comparou um grupo que praticou por três meses a respiração lenta e outro grupo a respiração rápida. Os resultados mostraram que no grupo de respiração lenta houve uma significativa redução na frequência cardíaca basal e aumento da atividade do nervo vagal, já no grupo de respiração rápida não houve qualquer alteração nesses parâmetros. Esse aumento na atividade do nervo vagal foi correlacionado com indivíduos mais gentis, alegres e melhor manejo do stress (Kok \& Fredrickson, 2010).

\section{A Relevância do Trabalho com a Cognição e as Emoções no Contexto Escolar}

Segundo estatísticas da Organização Mundial da Saúde (OMS), 20\% dos adolescentes terá algum problema de saúde mental, sendo 17\% depressão (Who, 2011). Este quadro é especialmente preocupante porque a depressão na adolescência aumenta a probabilidade de a depressão reincidir na idade adulta, com uma taxa de $40 \%$ dentro de dois anos, chegando a $70 \%$ em 5 anos (Keenan-Miller, Hammen, \& Brennan, 2007).
Os antidepressivos correspondem a uma indústria multibilionária, entretanto, seu efeito médio é apenas $20 \%$ melhor do que um placebo, sendo, portanto, uma melhora muito pequena para ser clinicamente significativa (Kirsch, Moore, Scoboria, \& Nicholls, 2002). Somam-se a isso estatísticas apontando que quase $50 \%$ das pessoas irão brigar com pensamentos suicidas por pelo menos duas semanas em sua vida e quase $100 \%$ das pessoas irá considerar em algum momento da vida a ideia de se matar (Chiles \& Strosahl, 2004).

Diante deste quadro é relevante a sociedade encontrar formas de frear e reverter essa tendência, trabaIhando desde cedo no espaço escolar, temáticas voltadas ao desenvolvimento pessoal. Napoli, Krech e Holley (2005) indicam que incorporar programas de redução de estresse como parte do currículo escolar está associado à melhora no desempenho acadêmico, autoestima, humor, concentração e problemas de mau comportamento. Fisher (2006) destaca que alguns minutos de prática diária de atenção plena ou algumas vezes na semana resultam em estudantes que são mais bem sucedidos, além de criar um ambiente de aprendizado mais pacífico. Mendelson e cols. (2010) concluíram que abordagens baseadas em atenção plena são bem aceitas por estudantes e docentes e os resultados estão relacionados à redução do estresse gerado por ruminação, pensamentos intrusivos e descontrole emocional. Já Shapiro e cols. (2008) argumentam que, para estudar, é importante manter uma atenção prolongada e focada, porém, raramente os educadores ensinam como conseguir isso.

Deste modo, a atenção plena apresenta relevância para o contexto escolar podendo ser aplicada como intervenção principal ou adicionada a programas já existentes. Seu caráter universal e transdiagnóstico, envolvendo tanto a patologia quanto a saúde, permite uma grande flexibilidade de trabalho e espectro de atuação.

\section{Método}

A fim de identificar as intervenções contemporâneas que poderiam servir de referência para a construção de intervenções no contexto escolar brasileiro, buscou-se escoIher aquelas que já tivessem sido avaliadas em metanálises e utilizaram o método experimental do estudo clínico randomizado (ECR), que segundo Souza (2009) é um método poderoso na determinação da eficácia de uma intervenção.

A primeira etapa consistiu em pesquisar (janeiro de 2017) na base de literatura psicológica Psyc/NFO o termo "mindfulness AND schools AND meta-analysis" tendo o retorno de três artigos sendo que um deles não tinha relação com o contexto escolar restando então o trabalho de Zenner e cols.(2014) e Zoogman e cols.(2015).

A segunda etapa foi identificar nas duas metanálises quais trabalhos avaliados eram ECRs. Em Zenner e cols. (2014), das 24 pesquisas avaliadas, 10 atendiam ao critério. Destes, não foi possível obter acesso gratuito a um deles, portando para este trabalho selecionaram-se os outros 9 
artigos. Já em Zoogman e cols. (2015), dos 20 estudos apresentados sete não eram ECRs e três não tinham relação com o contexto escolar, restando10 para análise. Dos 19 trabalhos, seis apareceram nas duas metanálises, tendo assim, 13 trabalhos distintos. Destes, dois não foram considerados ECRs por Zenner e cols. (2014), porém, foram por Zoogman e cols.(2015), e neste caso, optou-se por incluí-los. Ao final, o universo de análise ficou configurado por 15 artigos.

$\mathrm{Na}$ terceira e última etapa de filtragem buscou-se quais estudos disponibilizavam detalhes da intervenção utilizada, seja por usarem algum programa já digitalizado e disponível na internet ou em publicação (livro, artigo etc.),ou por apresentarem detalhes de encontro a encontro no próprio trabalho.

Assim, sete dos 15 artigos encaixaram-se nos critérios acima, e nestes, identificaram-se cinco programas de intervenção distintos que foram analisados neste trabalho: Attention Academy Program, InnerKids, Learning to Breathe, Meditación-Fluir e MBSR (Programa mindfulness para redução do estresse). Uma síntese deles pode ser encontrada no Quadro 1 a seguir.

$\mathrm{Na}$ avaliação dos programas foi dada especial atenção aos seguintes itens: estrutura (frequência, número e duração de encontros e carga horária total), faixa etária, tarefa de casa, o enfoque temático dos encontros e país de origem.

\section{Programas de Desenvolvimento da Atenção Plena - Attention Academy Program (AAP)}

O programa americano AAP tem a missão de ajudar estudantes a melhorar sua qualidade de vida através da prática da atenção plena. Os objetivos são promover o aprendizado à (1) atenção à experiência presente, (2) abordar cada experiência sem julgamentos e (3) ver cada experiência como nova e com "olhos de principiante". O programa não estipula um número definido de encontros nem sua duração, porém, indica uma estrutura de 4 partes a ser seguida a cada encontro: 1) discussão sobre atenção plena; 2) prática de exercícios de respiração (ex. contar respiração, respiração em 3 partes) 3) prática de atividades físicas (ex. alongamento, dança, caminhada); 4) práticas sensoriais (ex. notar cheiros, sons) (Napoli \& cols., 2005).

$\mathrm{Na}$ intervenção de Napoli e cols.(2005) baseada no programa Attention Academy avaliou-se o efeito da prática da atenção plena em várias medidas da atenção. Participaram um total de 97 alunos da $1^{\text {a }}$ a $3^{\text {a }}$ séries no grupo de intervenção. Houve12 encontros, duas vezes por mês, com 45 minutos de duração e carga horária total de 9h. Os resultados mostraram aumento da atenção seletiva, ou seja, a habilidade em escolher em o que prestar a atenção, além da redução do estresse e de comportamentos de hiperatividade.

Quadro 1. Visão geral dos programas analisados

\begin{tabular}{|c|c|c|c|c|c|}
\hline Programa & Estrutura & $\begin{array}{c}\text { Carga } \\
\text { horária }\end{array}$ & Estudos & $\begin{array}{l}\text { Faixa } \\
\text { etária }\end{array}$ & País \\
\hline Attention Academy & $\begin{array}{l}12 \text { encontros, } 2 x \\
\text { por mês } \\
45 \text { min cada }\end{array}$ & $9 \mathrm{~h}$ & Napoli e cols. (2005) & $6-9$ & EUA \\
\hline InnerKids & $\begin{array}{l}16 \text { encontros, } 2 x \\
\text { por semana } \\
30 \text { min cada }\end{array}$ & $8 \mathrm{~h}$ & Flook e cols. (2010) & $7-9$ & EUA \\
\hline Learning to Breathe & $\begin{array}{l}6 \text { encontros } \\
1 \times \text { por semana } \\
45 \text { min cada } \\
5-15 \text { min práticas } \\
\text { diárias em casa. }\end{array}$ & $4,5 \mathrm{~h}$ & Potek (2012) & $14-17$ & EUA \\
\hline Meditación-Fluir & $\begin{array}{l}10 \text { encontros, } 1 x \\
\text { por semana, } \\
1 \text { h30 cada } \\
30 \text { min práticas } \\
\text { diárias em casa. }\end{array}$ & $15 \mathrm{~h}$ & $\begin{array}{l}\text { Justo (2009) } \\
\text { Justo e cols. (2011a) } \\
\text { Justo e cols. (2011b) }\end{array}$ & $15-18$ & Espanha \\
\hline MBSR adaptado & $\begin{array}{l}4 \text { encontros } \\
1 \times \text { por semana } \\
40 \text { min cada } \\
8 \text { min } \\
\text { práticasdiárias em } \\
\text { casa. }\end{array}$ & $2,6 \mathrm{~h}$ & $\begin{array}{l}\text { Huppert \& Johnson } \\
\text { (2010) }\end{array}$ & $14-15$ & EUA \\
\hline
\end{tabular}


É importante destacar que os dois instrutores participantes da intervenção tiveram treinamento formal em centros de treinamento em atenção plena, apesar do programa indicar que a autoeducação através de leituras e práticas diárias em casa também é forma válida para qualificar-se. Este estudo sugere também que o melhor custo-benefício para integrá-lo no currículo é através das aulas de Educação Física, visto que todos os alunos participam desta disciplina, além de os professores dessa disciplina serem em menor número, portanto, havendo menos pessoas para qualificar.

\section{Innerkids}

O programa InnerKids foi desenvolvido por Susan Kaiser-Greenland (Kaiser-Greenland, 2016) e tem por objetivo aumentar a atenção e consciência ao momento presente e a percepção das experiências internas (que inclui tanto pensamentos e emoções quanto sensoriais) e externas, aprendendo também a distinguir uma da outra, usando para tal diversos jogos e atividades.

Também aborda os temas da gentileza, compaixão, equilíbrio e trabalho em equipe. Muitas das atividades são baseadas em movimentos corporais e envolvem a interação entre os participantes. Cada encontro deve ser dividido em três partes principais: 1) breve período de prática sentada de introspecção (aprox. três min); 2) atividades e jogos que buscam trabalhar o tema do encontro, como por exemplo, a consciência da respiração, dos sentidos, gentileza, trabalho em equipe ou compaixão; 3) período mais longo de ativida- de introspectiva, geralmente deitado (aprox. cinco min). À medida que os encontros avançam, o período de tempo em atividades introspectivas ( $1^{\mathrm{a}}$ e $3^{\mathrm{a}}$ partes) aumenta até tomar a maior parte do encontro. Detalhes do protocolo desse programa, incluindo exemplos de encontros, estão presentes no apêndice de Flook e cols. (2010). Por conveniência é apresentado no Quadro 2 um sumário das quatro etapas em que o programa é estruturado, podendo cada uma delas ocupar de um a quatro encontros.

O programa InnerKids é avaliado em Flook e cols. (2010). Neste trabalho estruturou-se a intervenção ao longo de oito semanas, sendo dois encontros semanais de $30 \mathrm{mi}-$ nutos cada. Os participantes foram alunos de 7 a 9 anos $\left(2^{\mathrm{a}}\right.$ e $3^{a}$ série do K12) de uma escola nos EUA, de grupo étnico diversificado.

Sobre os benefícios do programa encontrados no estudo, segundo questionário respondido por pais e docentes, houve melhora na regulação do comportamento, metacognição e funções executivas. No caso das funções executivas, os alunos com piores scores pré-teste, neste quesito foram os que apresentaram as maiores melhoras.

\section{Learning to Breathe}

O programa Learning to Breathe (Broderick, 2013) consiste em seis encontros semanais, com duração de 40 a 45 minutos, que foi adaptado do programa mindfulness para redução de estresse (MBSR) (Kabat-Zinn, 2013) para atender às demandas de desenvolvimento específicas da

Quadro 2. Estrutura do programa InnerKids. Fonte: Flook e cols. (2010).

\begin{tabular}{|c|c|c|}
\hline Etapa & Práticas para tomada de consciência & $\begin{array}{l}\text { Práticas de gentileza e bondade } \\
\text { (autocompaixão) }\end{array}$ \\
\hline $\begin{array}{c}1 \\
\text { Consciências } \\
\text { das experiências } \\
\text { internas, foco na } \\
\text { respiração. }\end{array}$ & $\begin{array}{l}\text { Objetivo: Desenvolver o contato com } \\
\text { o momento presente e da respiração } \\
\text { consciente e impermanência (tudo está } \\
\text { sempre em mudança). } \\
\text { Atividades típicas que promovem consciência } \\
\text { das experiências são jogos em que crianças } \\
\text { observam pensamentos, sentimentos e } \\
\text { sensações físicas à medida em que surgem } \\
\text { e vão embora. }\end{array}$ & $\begin{array}{l}\text { Objetivo: Desenvolver uma compreensão do } \\
\text { momento presente e de ampliar a bondade } \\
\text { para si mesmo. } \\
\text { Atividades típicas são visualizações guiadas } \\
\text { onde a criança imagina-se em um lugar seguro } \\
\text { em que se sente feliz, saudável, forte e segura. }\end{array}$ \\
\hline $\begin{array}{c}2 \\
\text { Consciência das } \\
\text { experiências } \\
\text { internas focando } \\
\text { nas percepções } \\
\text { dos sentidos. }\end{array}$ & $\begin{array}{l}\text { Objetivo: Desenvolver um contato com o } \\
\text { momento presente e uma compreensão da } \\
\text { natureza mutável da experiência interior, } \\
\text { enfatizando impressões sensoriais e vendo } \\
\text { claramente a experiência interior sem viés. } \\
\text { As atividades típicas que promovem a } \\
\text { percepção das impressões dos sentidos e } \\
\text { do corpo são práticas de alimentação atenta, } \\
\text { da atenção plena ao som e na atenção ao } \\
\text { toque. }\end{array}$ & $\begin{array}{l}\text { Objetivo: Desenvolver uma compreensão } \\
\text { e percepção de estender bondade para os } \\
\text { outros. } \\
\text { Atividades típicas que promovem bondade } \\
\text { para os outros são visualizações guiadas onde } \\
\text { uma criança imagina-se convidando pessoas } \\
\text { para um lugar seguro onde todos estão felizes, } \\
\text { saudáveis, seguros e fortes. }\end{array}$ \\
\hline
\end{tabular}


(cont.)

\begin{tabular}{|c|c|c|}
\hline $\begin{array}{c}3 \\
\text { Consciência das } \\
\text { experiências } \\
\text { internas e } \\
\text { externas focando } \\
\text { nos pensamentos } \\
\text { e emoções. }\end{array}$ & $\begin{array}{l}\text { Objetivo: Desenvolver uma compreensão } \\
\text { e percepção da natureza mutável da } \\
\text { experiência interna e externa, enfatizando } \\
\text { a consciência dos pensamentos, emoções } \\
\text { e uma compreensão de que as ações têm } \\
\text { consequências. } \\
\text { As atividades típicas que promovem a } \\
\text { consciência da experiência interna e externa } \\
\text { são os jogos onde as crianças observam } \\
\text { pensamentos, emoções e sensações físicas } \\
\text { à medida em que vêm, vão e mudam. }\end{array}$ & $\begin{array}{l}\text { Objetivo: Desenvolver uma compreensão e } \\
\text { percepção de estender a outros a compaixão } \\
\text { e felicidade. } \\
\text { Atividades típicas que promovem compaixão } \\
\text { e alegria são visualizações guiadas onde uma } \\
\text { criança imagina outras pessoas em situações } \\
\text { onde elas estão felizes, saudáveis, seguras e } \\
\text { vivendo em paz. }\end{array}$ \\
\hline $\begin{array}{c}4 \\
\text { Consciência das } \\
\text { experiências } \\
\text { internas e } \\
\text { externas sem } \\
\text { misturar as } \\
\text { duas, focando } \\
\text { na interconexão } \\
\text { e serviço aos } \\
\text { outros. }\end{array}$ & $\begin{array}{l}\text { Objetivo: Desenvolver uma compreensão } \\
\text { e percepção da experiência externa } \\
\text { enfatizando a consciência de outras pessoas, } \\
\text { do ambiente e da impermanência. } \\
\text { Atividades típicas que promovem a } \\
\text { conscientização da experiência externa e da } \\
\text { sintonia com outras pessoas são práticas de } \\
\text { espelhamento em que as crianças imitam (ou } \\
\text { espelham) os movimentos físicos de outros } \\
\text { alunos. }\end{array}$ & $\begin{array}{l}\text { Objetivo: Desenvolver uma compreensão } \\
\text { e percepção de equanimidade, equilíbrio e } \\
\text { interconexão. } \\
\text { Uma atividade típica que promove a } \\
\text { interconexão é sugerir que a criança imagine } \\
\text { uma maçã desde a semente até o estômago. } \\
\text { Primeiro a criança a imagina como uma } \\
\text { semente, depois a semente que está sendo } \\
\text { plantada, e então observa como a luz e a chuva } \\
\text { ajudaram a semente a crescer em uma árvore } \\
\text { que deu fruto. Então imagina a maçã como } \\
\text { ela foi colhida, levado para a loja, comprado, } \\
\text { lavado e embalado em sua lancheira por mãe, } \\
\text { pai ou responsável. }\end{array}$ \\
\hline
\end{tabular}

adolescência. Estudos preliminares por Broderick (2013) mostram que o programa foi bem sucedido em melhorar reclamações somáticas, regulação emocional, diminuição da negatividade e ajudou adolescentes a sentirem-se mais relaxados, calmos e a aceitarem-se (Potek, 2012).O programa é apresentado de forma resumida no Quadro 3.

Em Potek (2012) o programa Learning to Breathe é avaliado em duas escolas de ensino médio nos EUA, havendo estudantes de diferentes faixas socioeconômicas. Em termos de faixa etária tem-se alunos de 14 a 17 anos (48\% do sexo feminino) da $9^{\mathrm{a}}$ a $12^{\mathrm{a}}$ séries do $\mathrm{K} 12$.

Neste estudo, o instrutor do programa completou um treinamento básico em programa mindfulness de redução de estresse (MBSR) além de ser um instrutor de yoga certificado. Os encontros incluíam discussões sobre a tarefa de casa, introdução a uma habilidade específica e rápida prática desta habilidade, prática mindfulness formal encerrando com uma discussão em grupo e perguntas. Nesta intervenção, as sessões duravam aproximadamente 50 minutos. Os resultados apresentados apontam redução significativa do estresse e ansiedade.

\section{Meditación-Fluir}

O programa Meditación-fluir foi desenvolvido pelos próprios autores dos estudos e avaliado em três trabalhos de estudos clínicos randomizados (Justo, 2009; Justo,
Mañas, Cangas, \& Gallego, 2011a; Justo, Arias, \& Granados, 2011b). Tem por objetivo principal aprender a não tentar controlar os pensamentos, nem alterar ou substituí-los por outros, mas deixá-los fluir livremente, aceitando qualquer decorrência deles, enquanto traz-se a atenção ao momento presente. O programa compreende 10 encontros semanais de 1 h30 além de prática diária de 30 minutos fora dos encontros. Cada sessão inicia-se com trinta minutos de meditação fluir, e segue com a apresentação de metáforas e exercícios tomadas a partir da Terapia de Aceitação e Compromisso (Hayes \& cols., 2012) juntamente com contos da tradição Zen (Deshimaru, 2002) e Vipassana (Hart, 2003), a fim de aprenderem a distanciar-se dos pensamentos, sentimentos e emoções, observando-os de forma imparcial, sem se envolver ou influenciar o seu conteúdo. Detalhes de sessão a sessão são apresentados no Quadro 4.

No estudo de Justo (2009) aplica-se o programa direcionado a estudantes de 15 a 18 anos do $1^{\circ}$ e $2^{\circ}$ anos do ensino médio de três escolas públicas na Espanha. $\mathrm{O}$ principal benefício apresentado foi uma melhora nos níveis de criatividade verbal (fluidez, flexibilidade e originalidade). Na pesquisa de Justo e cols. (2011b) os participantes foram alunos do $1^{\circ}$ e $2^{\circ}$ anos do ensino médio na faixa etária de 16 a 19 anos, tendo-se obtido resultados significativos nos níveis de autorrealização pessoal conforme mensurados pelo instrumento AURE (Questionário de Autoconceito e Autorrealização). Os dados mostraram que nas três dimensões de autorrealização mensurados (enfrentamento e resolução 
Quadro 3. Resumo do programa Learning to Breathe.

\begin{tabular}{|c|c|c|c|c|}
\hline Sessão & Mensagem principal & Objetivos & Atividades & Tarefa \\
\hline Sessão 1 - B & $\begin{array}{l}\text { Body (Corpo) } \\
\text { "Ouça! Seu corpo está } \\
\text { tentando te dizer algo!" }\end{array}$ & $\begin{array}{l}\text { 1. Introduzir os acrônimos do } \\
\text { programa BREATHE } \\
\text { 2. Descrever o que atenção } \\
\text { plena significa } \\
\text { 3. Experienciar a maneira } \\
\text { como o corpo guarda tensão } \\
\text { e praticar a consciência da } \\
\text { respiração e do corpo. }\end{array}$ & $\begin{array}{l}\text { Atividade } 1 \text { - Focar na } \\
\text { atenção plena através da } \\
\text { consciência dos sons e } \\
\text { paladar e discutir o conceito } \\
\text { de "piloto automático". } \\
\text { Atividade } 2 \text { - Discussão } \\
\text { sobre Atenção plena X } \\
\text { Desatenção e prática de } \\
\text { respiração }\end{array}$ & $\begin{array}{l}\text { 1. Prática diária de } \\
\text { respiração consciente. } \\
\text { 2. Prática da varredura do } \\
\text { corpo com o CD uma vez } \\
\text { ao dia. }\end{array}$ \\
\hline Sessão 2 - R & $\begin{array}{l}\text { Reflexões } \\
\text { (Pensamentos) } \\
\text { "Pensamentos são só } \\
\text { pensamentos" }\end{array}$ & $\begin{array}{l}\text { 1. Dramatizar a maneira como } \\
\text { a mente vaga. } \\
2 \text {. O efeito do pensamento } \\
\text { sobre a atenção e os } \\
\text { sentimentos } \\
\text { 3. Discriminar entre } \\
\text { pensamentos positivos e } \\
\text { negativos. }\end{array}$ & $\begin{array}{l}\text { Atividade } 1 \text { - Como os } \\
\text { pensamentos e emoções } \\
\text { estão conectados } \\
\text { Atividade } 2 \text { - Role play } \\
\text { sobre como o autodiálogo } \\
\text { pode mudar a maneira como } \\
\text { pensamos e sentimos. }\end{array}$ & $\begin{array}{l}\text { 1. Prática diária de } \\
\text { respiração consciente. } \\
\text { 2. Prática da meditação } \\
\text { do pensamento com o CD } \\
\text { uma vez ao dia. }\end{array}$ \\
\hline Sessão 3 - E & $\begin{array}{l}\text { Emoções } \\
\text { "Aprender a gerenciar } \\
\text { os sentimentos através } \\
\text { da compreensão da } \\
\text { forma como eles vêm } \\
\text { e vão" }\end{array}$ & $\begin{array}{l}\text { 1. Entender o papel que os } \\
\text { sentimentos têm na sensação } \\
\text { de bem-estar e poder pessoal. } \\
\text { 2. Entender e experimentar o } \\
\text { surgimento e desaparecimento } \\
\text { das emoções. } \\
\text { 3. Aprender a gerenciar } \\
\text { as emoções através da } \\
\text { observação dos pensamentos. }\end{array}$ & $\begin{array}{l}\text { Atividade } 1 \text { - "Surfar a onda } \\
\text { das emoções" exercício para } \\
\text { observar emoções sem- } \\
\text { julgamentos. } \\
\text { Atividade } 2 \text { - Exploração } \\
\text { de como pensamentos, } \\
\text { sentimentos e sensações } \\
\text { estão associados com o } \\
\text { humor. }\end{array}$ & $\begin{array}{l}\text { 1. Prática diária de } \\
\text { respiração consciente. } \\
\text { 2. Prática da meditação } \\
\text { do pensamento com o CD } \\
\text { uma vez ao dia. } \\
\text { 3. Começar a perceber } \\
\text { pensamentos, sentimentos } \\
\text { e sensações à medida que } \\
\text { surgem ao longo do dia. }\end{array}$ \\
\hline Sessão 4 - A & $\begin{array}{l}\text { Atenção } \\
\text { "Atenção ao corpo, } \\
\text { pensamentos e } \\
\text { sentimentos é uma } \\
\text { boa maneira de reduzir } \\
\text { estresse" }\end{array}$ & $\begin{array}{l}\text { 1. Entender conceitos e } \\
\text { fundamentos sobre estresse } \\
\text { e as respostas do corpo ao } \\
\text { mesmo. } \\
\text { 2. Integrar conhecimentos } \\
\text { sobre pensamentos, } \\
\text { sentimentos e sensações com } \\
\text { a compreensão dos processos } \\
\text { de estresse. } \\
\text { 3. Trazer a atenção plena aos } \\
\text { estressores na vida pessoal. }\end{array}$ & $\begin{array}{l}\text { Atividade } 1 \text { - Jogo } \\
\text { para discutir conceitos } \\
\text { relacionados ao estresse e } \\
\text { explorar as suas causas e } \\
\text { efeitos. } \\
\text { Atividade } 2 \text { - Estudantes } \\
\text { registram seu funcionamento } \\
\text { em diversas áreas e praticam } \\
\text { movimento consciente. }\end{array}$ & $\begin{array}{l}\text { 1. Prática diária de } \\
\text { respiração consciente. } \\
\text { 2. Prática da meditação } \\
\text { do movimento consciente } \\
\text { uma vez ao dia à partir da } \\
\text { consulta ao material do } \\
\text { aluno. } \\
\text { 3. Começar a perceber } \\
\text { pensamentos, sentimentos } \\
\text { e sensações à medida que } \\
\text { surgem ao longo do dia. }\end{array}$ \\
\hline Sessão 5 - T & $\begin{array}{l}\text { Tome as coisas como } \\
\text { são } \\
\text { (não-julgamento) } \\
\text { "Aprenda a ser gentil } \\
\text { consigo mesmo" }\end{array}$ & $\begin{array}{l}\text { 1. Identificar as maneiras como } \\
\text { indivíduos estão consciente e } \\
\text { inconscientemente falhando em } \\
\text { cuidar de si mesmos. } \\
\text { 2. Entender uma abordagem } \\
\text { preventiva sobre autocuidado. } \\
\text { 3. Experienciar como cultivar } \\
\text { e praticar pensamentos e } \\
\text { sentimentos benéficos. }\end{array}$ & $\begin{array}{l}\text { Atividade } 1 \text { - Ler em voz } \\
\text { alta um texto sobre como } \\
\text { podemos ser maldosos } \\
\text { com nós mesmos, e então, } \\
\text { separar estudantes em } \\
\text { pequenos grupos a fim de } \\
\text { explorar maneiras como se } \\
\text { pratica comportamentos } \\
\text { destrutivos consigo e com os } \\
\text { outros. } \\
\text { Atividade } 2 \text { - Prática da } \\
\text { meditação da gentileza } \\
\text { consigo. }\end{array}$ & $\begin{array}{l}\text { 1. Prática diária de } \\
\text { respiração consciente. } \\
\text { 2. Prática da meditação da } \\
\text { gentileza uma vez ao dia, } \\
\text { usando CD. } \\
\text { 3. Começar a perceber } \\
\text { pensamentos, sentimentos } \\
\text { e sensações à medida que } \\
\text { surgem ao longo do dia. } \\
\text { Atenção às autocríticas. }\end{array}$ \\
\hline Sessão 6 - H & $\begin{array}{l}\text { Hábitos para uma mente } \\
\text { saudável } \\
\\
\text { "Encontrar maneiras de } \\
\text { praticar atenção plena } \\
\text { em sua vida reduz } \\
\text { estresse e aumenta a } \\
\text { força interior" }\end{array}$ & $\begin{array}{l}\text { 1. Identificar maneiras de } \\
\text { praticar atenção plena no dia- } \\
\text { a-dia. } \\
\text { 2. Discutir maneiras para } \\
\text { desenvolver uma prática } \\
\text { pessoal em atenção plena. } \\
\text { 3. Revisão dos principais } \\
\text { pontos deste curso. }\end{array}$ & $\begin{array}{l}\text { Atividade } 1 \text { - Em pequenos } \\
\text { grupos, os alunos exploram } \\
\text { Dez maneiras para ficar } \\
\text { estressado como forma de } \\
\text { revisar tópicos importantes, } \\
\text { com humor. } \\
\text { Atividade } 2 \text { - Integrar a } \\
\text { prática da atenção plena }\end{array}$ & 1. Escolha pessoal \\
\hline
\end{tabular}

Objetivo geral do Empoderamento

programa - E

Fonte: Potek(2012). 
Quadro 4. Resumo do programa Meditación-Fluir.

\begin{tabular}{|c|c|c|}
\hline Sessão & Exercícios & Metáforas \\
\hline 1 & $\begin{array}{l}\text { - } \text { - Epresentação de todos os membros do grupo } \\
\text { - Exposição dos motivos para participar do curso de meditação e as expectativas } \\
\text { - } \text { aspectos a levarem em conta relação à prática da meditação. } \\
\text { - Explicação sobre a prática da meditação-fluir } \\
\text { - Realização da } 1^{\text {a }} \text { prática de meditação } \\
\text { - Exercício de tentar não piscar durante um minuto }\end{array}$ & \\
\hline 2 & $\begin{array}{l}\text { - Exercício de tentar não piscar durante um minuto } \\
\text { - } \quad \text { Buscar antologias entre o exercício anterior e o controle de eventos privados } \\
\text { - } \quad \text { Prática de meditação }\end{array}$ & Metáfora do bambu \\
\hline 3 & $\begin{array}{l}\text { - Exercício de observação de sensações no rosto } \\
\text { - Prática de meditação }\end{array}$ & $\begin{array}{l}\text { Metáfora do Rio, } \\
\text { Metáfora do vidro sujo, } \\
\text { Metáfora da Operação e } \\
\text { Metáfora do Parto com } \\
\text { Dor }\end{array}$ \\
\hline 4 & $\begin{array}{l}\text { - Exercício de observação de sensações nas áreas do peito e abdômen } \\
\text { - Prática de meditação }\end{array}$ & $\begin{array}{l}\text { Metáfora do Macaco e da } \\
\text { Banana }\end{array}$ \\
\hline 5 & $\begin{array}{l}\text { - Exercício de observação de sensações na área das costas } \\
\text { - Exercício de lembrar palavras } \\
\text { - Exercício de observação de pensamentos } \\
\text { - Exercício "Quais são os números" e "Como se chama sua mãe"? } \\
\text { - } \quad \text { Prática de meditação }\end{array}$ & $\begin{array}{l}\text { Metáfora dos dois } \\
\text { Monges }\end{array}$ \\
\hline 6 & $\begin{array}{l}\text { - Exercício de observar as sensações nos braços } \\
\text { - Exercício de contar pensamentos } \\
\text { - Prática de meditação }\end{array}$ & $\begin{array}{l}\text { História do } \\
\text { dois Anéis }\end{array}$ \\
\hline 7 & $\begin{array}{l}\text { - Exercício de observar as sensações nas pernas } \\
\text { - Prática de meditação }\end{array}$ & Metáfora do Rádio Ligado \\
\hline 8 & $\begin{array}{l}\text { - Exercício de observação de sensações perto do corpo } \\
\text { - Exercício para analisar os "tenho que..." e os "deveria..." }\end{array}$ & \\
\hline 9 & $\begin{array}{l}\text { - Exercício de aceitação de eventos privados chatos e desconfortáveis } \\
\text { - Exercício de decidir sim e não fazer assim como decidir não e fazer } \\
\text { - Prática de meditação }\end{array}$ & $\begin{array}{l}\text { Metáfora do Computador, } \\
\text { Metáfora do Polígrafo, } \\
\text { A história de Miáou }\end{array}$ \\
\hline 10 & - Prática de meditação & $\begin{array}{l}\text { Metáfora dos índios que } \\
\text { coletam lenha }\end{array}$ \\
\hline
\end{tabular}

Fonte: Justo, Arias, \& Granados, 2011.

de tarefas, autoconceito e autoestima, empatia e relacionamentos sociais) houve melhora significativa em comparação ao grupo controle. No estudo de Justo e cols.(2011a) os participantes foram alunos do ensino médio de escolas públicas da província de Almería na Espanha na faixa etária de 16 a 18. Avaliou-se a performance acadêmica, autoconceito e ansiedade obtendo-se melhoras significativas em todas estas variáveis.

\section{MBSR e MBSR Adaptado}

Desenvolvido nos anos 70 por Jon Kabat-Zinn, professor de Medicina da Universidade de Massachusetts, o programa Mindfulness para Redução do Stress tinha inicialmente o foco na redução de estresse em pacientes adultos hospitalizados. Ao longo do tempo cresceu muito em popularidade, 
sendo que em 2013, já se computavam 720 programas ao redor do mundo inspirados no MBSR (Kabat-Zinn, 2013).

O programa MBSR original é realizado em grupo e tem a duração de oito semanas, compreendendo encontros semanais de $2 \mathrm{~h}$, práticas diárias em casa de 45 minutos e entre os encontros 6 e 7 um retiro de dia inteiro com práticas que duram 6 horas no total. As práticas se dividem em três grupos: meditação mindfulness, varredura do corpo e posturas básicas de yoga.

No trabalho de Huppert \& Johnson (2010) empregou-se o MBSR, porém, em formato adaptado, encurtando-se o número de encontros de oito para quatro e a duração das sessões de duas horas para 40 minutos. Nos encontros abordaram-se progressivamente os conceitos de percepção e aceitação, e, dentre as práticas, incluíam-se a consciência corporal, a consciência da respiração encontrando nela um ponto de âncora, a consciência dos sons, a compreensão da natureza passageira dos pensamentos e a meditação caminhando. Também foi fornecido um CD especialmente concebido, contendo três arquivos de áudio de oito minutos de exercícios de atenção plena para ser usado fora da sala de aula. Esses arquivos de áudio refletiam os aspectos progressivos do treinamento que os alunos estavam recebendo em sala de aula. Os alunos foram incentivados a realizar a prática diária ouvindo os arquivos de áudio apropriados (Huppert \& Johnson, 2010).

Os resultados do estudo mostram que houve meIhora significativa nas medidas de atenção plena e bem-estar psicológico para os $1 / 3$ dos participantes que mantinham uma prática fora dos encontros (três ou mais vezes por semana), tendo o restante do grupo não apresentado meIhora significativa quando comparado ao grupo controle. Os autores concluem que a intervenção é promissora e poderia ter seu tempo ampliado (2,6 horas neste formato versus 16 horas do MBSR original), pois o estudo apresentou uma correlação positiva entre maior tempo de prática e melhora das medidas avaliadas.

\section{Discussão}

Através do estudo das metanálises foi possível observar uma grande variedade de estudos clínicos avaliando intervenções em atenção plena no contexto escolar, tendo estes uma variedade de ambientes, metodologias e instrumentos que exploram diferentes aspectos psicológicos. Esta variedade é talvez reflexo da novidade do tema no meio acadêmico fazendo com que pesquisadores experimentem o uso da atenção plena para os mais variados fins na expectativa que esta se mostre útil.

Dado esse cenário, apesar da intenção inicial do autor fosse buscar "o melhor" programa, a comparação direta entre eles tornou-se inviável e nenhum mostrou clara vantagem sobre a outro. Este trabalho objetivou levantar e discutir os cinco programas de intervenção que estivessem disponíveis ao público e apresentassem algum nível de eficácia comprovada através de estudo clínico randomizado. A eventual escolha de um ou outro programa provavelmente se dará mais pela formação técnica do corpo de profissionais disponível na escola além da disponibilidade de tempo para se determinar a frequência e duração ideal. Por exemplo, no quesito formação, a intervenção Meditación-Fluir utiliza-se de conhecimentos da Terapia de Aceitação e Compromisso e Zen budismo o que reflete numa maior exigência de qualificação. Já a duração das intervenções variou entre um a seis meses, o que mostra uma flexibilidade para diferentes calendários acadêmicos.

Assim, os itens escolhidos para avaliação foram: estrutura (frequência, número e duração de encontros e carga horária total), faixa etária, tarefa de casa, o enfoque temático dos encontros e país de origem.

Na faixa etária de crianças de 6 a 9 anos, o programa InnerKids foi estruturado em dois encontros por semana de 30 minutos ao longo de oito semanas (C.H. 8h). Já o Attention Academy a frequência dos encontros era mais espaçada, sendo duas vezes por mês com 45 minutos cada, porém,distribuindo-se ao longo de 24 semanas (C.H. 9h). Nenhum dos dois passava tarefa de casa.

Nos três programas direcionados ao público adolescentes (14-18 anos) a frequência manteve-se a mesma, uma vez por semana, porém variou-se a duração, sendo 45 min para Learning to Breathe, 1h30 para Meditación-Fluir e 40 min para MBSR adaptado. Todos passavam tarefas de casa com duração de 5-15min, 30min e 8min respectivamente.

A duração dos programas pode ter sido fator relevante no sucesso das intervenções. Na intervenção de menor duração, MBSR adaptado, os autores entenderam que o pouco tempo de prática pode ter influenciado no resultado não significativo para o grupo de participantes que não se engajaram nas tarefas de casa e, portanto, só tinham as poucas horas de práticas em grupo $(2,6 \mathrm{~h})$. Encontrou-se também uma correlação positiva entre melhora significativa e tempo de prática em casa, com destaque para a abrangência dos bons resultados do Meditación-Fluir, programa com maior carga horária (15h em grupo e 30 min diários em casa).

Outro destaque do programa Meditacion-Fluirfoi sua avaliação em três ensaios clínicos randomizados tendo estes apresentado melhorias significativas em uma variedade de medidas: criatividade verbal, autorrealização pessoal nas suas três dimensões (enfrentamento e resolução de tarefas, autoconceito e autoestima, empatia e relacionamentos sociais), performance acadêmica, auto-conceito e ansiedade.

Avaliando-se o enfoque dos temas abordados em cada encontro, Attention Academy tem uma forte inspiração na yoga, trabalhando bastante movimentos corporais e respiração. Já o InnerKids focou na promoção da autoconsciência e percepção do outro através de práticas como imaginação guiada, atenção as sensações no corpo, bondade-gentileza e empatia. Em Learning to Breathe trabalharam-se práticas relacionadas à exploração do corpo, respiração, efeitos do pensamento e sentimentos sobre o comportamento, estresse, o conceito de "piloto automático" e também a prática da gentileza e a reflexão sobre comportamentos destruti- 
vos consigo e outros. No programa Meditación-Fluir foram abordados exercícios e metáforas da Terapia de Aceitação e Compromisso, da tradição Zen e Vipassana, portanto, trabaIhando tópicos como impermanência, esquiva experiencial, agenda de controle de sentimentos e emoções, além de ação comprometida. No MBSR adaptado trabalharam-se a percepção e a aceitação, práticas de consciência corporal, consciência da respiração encontrando nela um ponto de âncora, consciência dos sons, a compreensão da natureza passageira dos pensamentos e meditação caminhando.

$\mathrm{O}$ último item avaliado nos programas foi quanto à nacionalidade, e neste, observa-se que apenas o programa Meditación-Fluir é espanhol sendo os outros quatro programas estadunidenses, evidenciando a necessidade de expansão dos programas e das pesquisas desta área para outros países.

Informações sobre a adesão e aceitação das intervenções pelos participantes foram fracas, tendo apenas Huppert \& Johnson (2010) e Potek (2012) aplicado questionário de avaliação. O primeiro estudo lançou mão de cinco perguntas e avaliou a facilidade e eficácia do aprendizado, agradabilidade, tempo de duração e importância da prática.O segundo estudo utilizou-se do grau de satisfação geral para avaliar se este teria um efeito moderador sobre as variáveis em estudo (estresse, ansiedade etc.), o que impossibilitou ter acesso ao dado qualitativo bruto. Um item destacado por ambos foi a duração da intervenção. Em Huppert \& Johnson (2010) a duração foi considerada reduzida para $43 \%$, adequada para $52 \%$ e apenas $5 \%$ acharam longa, confirmando a preocupação já levantada pelos autores de que o tempo poderia ser maior. Potek (2012) parece corroborar a questão do tempo reduzido ao destacar algumas falas dos participantes: "Nós apenas começamos a entender. Eu acho que precisamos de mais tempo de prática", "Eu queria que o programa durasse todo o semestre" e "Eu gostei, mas acho que foi muito curto".

\section{Conclusão}

O presente estudo teve como objetivo geral investigar a prática da atenção plena em contexto escolar. Para tanto, tomou-se como base dois estudos de metanálise que enfocaram atenção plena na escola, de Zenner e cols. (2014) e de Zoogman e cols.(2015). Do universo de estudos apresentados, escolheram-se aqueles que empregaram o método experimental do estudo clínico randomizado e disponibilizaram detalhes da intervenção utilizada, resultando ao final sete artigos e cinco programas distintos.

Foram duas intervenções voltadas para crianças dos 6 a 9 anos e três direcionadas a adolescentes (14 a 18 anos). Houve uma importante variação na estrutura dos programas e na carga horária total. Os programas que tinham o foco na infância não aplicavam tarefa de casa enquanto os para adolescentes o tempo das tarefas diárias variava entre 5 a 30 minutos. O conteúdo abordado nos programas também variou. Um focou mais em movimentos corporais inspirados na Yoga, outro em ensinamentos da tradição filosófica oriental e um terceiro em autoconscientização e práticas de bondade-gentileza.

As intervenções, em sua grande maioria, mostraram resultados significativos em diversas dimensões de análise como por exemplo diminuição do estresse e ansiedade, aumento da autorrealização, criatividade verbal e performance acadêmica, melhora na regulação do comportamento e autoconceito,e incremento da atenção seletiva.

Assim, pode-se concluir a partir deste levantamento que a atenção plena no contexto escolar é relevante e mostrou-se eficaz. Este trabalho também evidenciou que as intervenções são bastante diversas e em sua maioria transposições das práticas realizadas com adultos havendo pequenas alterações no formato da apresentação. Outro desafio foi o fato dos estudos usarem instrumentos distintos de mensuração o que dificulta uma comparação de eficácia direta das diferentes intervenções. Mostrou também que falta uma teoria explicativa acerca do que acontece e o que se busca em termos cognitivos, emocionais e neurofisiológicos com cada intervenção e de que modo os diversos componentes de uma intervenção atuam.

Percebe-se que há possibilidade de aprofundamento sobre o tema, pois à medida que novos estudos de intervenção são publicados, mais dados podem ser comparados e similaridades encontradas. Além disso, a definição de instrumentos padronizados de medição e uma teoria explicativa certamente irão auxiliar tanto na elaboração e aperfeiçoamento de intervenções como na avaliação de sua eficácia.

\section{Referências}

Assagioli, R. (2013). Psicossíntese: as bases da psicologia moderna e transpessoal. São Paulo, SP: Cultrix.

Bishop, S. R.; Lau, M.; Shapiro, S.; Carlson, L.; Anderson, N. D.; Carmody, J.;...Devins, G. (2004). Mindfulness: A proposed operational definition. Clinical Psychology: Science and Practice, 11(3), 230-241.

Bowen, S.; Chawla, N.; Marlatt, G. A. (2010). Mindfulness-Based Relapse Prevention for Addictive Behaviors: A Clinician's Guide. New York: Guilford Press.

Broderick, P. C. (2013). Learning to Breathe: A Mindfulness Curriculum for Adolescents to Cultivate Emotion Regulation, Attention, and Performance. Oakland, CA: New Harbinger Publications.

Brown, K. W.; Ryan, R. M. (2003). The benefits of being present: mindfulness and its role in psychological well-being. Journal of Personalityand Social Psychology, 84(4), 822-848.

Chiles, J. A.; Strosahl, K. D. (2004). Clinical Manual for Assessmentand Treatment of Suicidal Patients. Washington, DC: American Psychiatric Association.

Deshimaru, T. (2002). La prática del zen. Barcelona: RBA. 
Fisher, R. (2006). Still thinking: The case for meditation with children. Thinking Skills and Creativity, 1(2), 146-151.

Flook, L.; Smalley, S. L.; Kitil, M. J.; Galla, B. M.; Kaiser-Greenland, S.; Locke, J.; ... Kasari, C. (2010). Effects of Mindful Awareness Practices on Executive Functions in Elementary School Children. Journal of Applied School Psychology, 26(1), 70-95.

Germer, C. K.; Siegel, R. D.; Fulton, P. R. (2016). Mindfulness e Psicoterapia (2a ed.). Porto Alegre, RS: Artmed.

Gilbert, P. (2010). Compassion Focused Therapy: Distinctive Features. New York: Routledge.

Hart, W. (2003). La Vippasana. El arte de la meditación. Madrid: Luz do Oriente.

Hayes, S. C.; Strosahl, K.; Wilson, K. G. (2012). Acceptance and commitment therapy: the process and practice of mindful change (2a ed.). New York: Guilford Press.

Huppert, F. A.; Johnson, D. M. (2010). A controlled Trial of mindfulness training in schools: The importance of practice for animpact on well-being. The Journal of Positive Psychology, 5(4), 264-274.

Linehan, M. M. (2015). DBT Skills Training Manual (2nd ed.). New York, NY: The Guilford Press.

Justo, C. F. (2009). Efectos de un programa de meditación sobre los niveles de creatividad verbal sobre un grupo de alumnos / as de bachillerato. Suma Psicologica, 16(2), 113-120.

Justo, C. F.; Mañas, I.; Cangas, A. J.; Gallego, J. (2011a). Exploring the Effects of a Mindfulness Program for Students of Secondary School. International Journal of Knowledge Society Research, 2(1), 14-28.

Justo, C. F.; Fuente Arias, M.; Granados, M. S. (2011b). Impacto de un programa de entrenamiento en conciencia plena (mindfulness) en las medidas del crecimiento y la autorrealización personal. Psicothema, 23(1), 58-65.

Kabat-Zinn, J. (2003). Mindfulness-based interventions in context: Past, present, and future. Clinical Psychology: Science and Practice, 10(2), 144-156.

Kabat-Zinn, J. (2005). Comming to our senses: Healing ourselves and the world through mindfulness. New York: Hyperion.

Kabat-Zinn, J. (2013). Full Catastrophe Living (Revised Edition): Using the Wisdom of Your Body and Mind to Face Stress, Pain, andIIIness (2a ed.). New York: Bantam Books.

Kabat-Zinn, J.; Massion, A. O.; Kristeller, J.; Peterson, L. G.; Fletcher, K. E.; Pbert, L.; ... Santorelli, S. F. (1992). Effectivenes sof a meditationbased stress reduction program in the treatment of anxiety disorders. In American Journal of Psychiatry,(149), 936-943.
Kaiser-Greenland, S. (2016). Inner Kids program model. Recuperado: 20Fev. 2017.Disponível: http://www.susankaisergreenland.com/ inner-kids-model

Keenan-Miller, D.; Hammen, C. L.; Brennan, P. A. (2007). Health Outcomes Related to Early Adolescent Depression. Journal of Adolescent Health, 41(3), 256-262.

Kirsch, I.; Moore, T. J.; Scoboria, A.; Nicholls, S. S. (2002). The emperor's new drugs: Ananalysis of antidepressant medication data submitted to the U.S. Food and Drug Administration. Prevention \& Treatment, 5(1), 1-11.

Kok, B. E.; Fredrickson, B. L. (2010). Upward spirals of the heart: Autonomic flexibility, as indexed by vagal tone, reciprocally and prospectively predicts positive emotions and social connectedness. Biological Psychology, 85(3), 432-436.

Lazar, S. W. (2016). A neurobiologia de mindfulness. In: Germer, C. K.; Siegel, R. D.; Fulton, P. R. (Orgs.), Mindfulness e psicoterapia (p. 290-303). Porto Alegre, RS: Artmed.

Lizabeth, R.; Orsillo, S.M. (2010). A prática da terapia cognitivocomportamental baseada em mindfulness e aceitação. Porto Alegre, RS: Artmed.

Mendelson, T.; Greenberg, M. T.; Dariotis, J. K.; Gould, L. F.; Rhoades, B. L.; Leaf, P. J. (2010). Feasibility and preliminary outcomes of a school-based mindfulness intervention for urban youth. Journal of Abnormal Child Psychology, 38(7), 985-994.

Napoli, M.; Krech, P. R.; Holley, L. C. (2005). Mindfulness Training for Elementary School Students: The Attention Academy. Journal of Applied School Psychology, 21(1), 99-125.

Pal, G. K.; Velkumary, S.; Madanmohan, A. (2004). Effect of shortterm practice of breathing exercises on autonomic functions in normal human volunteers. Indian Journalof Medical Research, 120(2), 115-121.

Potek, R. (2012). Mindfulness as a school-based prevention programand its effect on adolescent stress, anxiety and emotion regulation. New York University.

Shapiro, S. L.; Brown, K. W.; Astin, J. A. (2008). Toward the integration of meditation into higher education: A reviewof research. Center for Contemplative Mind in Society. Recuperado: 20 Fev. 2017. Disponível: http://www.contemplativemind.org/admin/wp-content/ uploads/2012/09/MedandHigherEd.pdf

Silveira, A. D. C.; Castro, T. G.; Gomes, W. B. (2012). Adaptação e validação da Escala Filadélfia de Mindfulness para adultos brasileiros. Psico-USF, 17(2), 215-223.

Souza, R. F. (2009). O que é um estudo clínico randomizado? Medicina, 42(1), 3-8. 
Stewart, J. M. (2014). Mindfulness, Acceptance, and the Psychodynamic Evolution. Oakland, CA: New Harbinger Publications.

World Health Organization [WHO] (2011). Adolescents: health risks and solutions.Recuperado: 20 Fev. 2017. Disponível: http://www. who.int/mediacentre/factsheets/fs345/en/

Williams, M.; Penman, D. (2015). Atenção Plena: como encontrar a paz em um mundo frenético. Rio de Janeiro: Sextante.
Zenner, C.; Herrnleben-Kurz, S.; Walach, H. (2014). Mindfulnessbased interventions in schools - A systematic review and metaanalysis. Frontiers in Psychology, 5(June), 1-20.

Zoogman, S.; Goldberg, S. B.; Hoyt, W. T.; Miller, L. (2015). Mindfulness Interventions with Youth: A Meta-Analysis. Mindfulness, 6(2), 290302.

Recebido em: 19 de maio de 2017

Aceito em: 25 de abril de 2018 unrestricted use, distribution and reproduction in any medium, provided the original article is properly cited. 